\title{
A Comparison of TDN and Net Energy Calculations for Estimating Empty Body Weight Change for Beef Cows Using ADF, NRC-01 Lignin and TTNDFd Methodology
}

\section{DOI:10.31274/air.11805}

\author{
Garland Dahlke, Iowa Beef Center; \\ Devin Jakub, Graduate Research Assistant, Iowa State \\ University \\ John Goeser, Rock River Laboratory, Inc. \& University of \\ Wisconsin-Madison
}

\section{Summary and Implications}

Total tract neutral detergent fiber digestibility is a relatively new system for feed fiber quality evaluation and subsequent feed energy determination. This system has been proven to work in dairy cattle and also seems to work considerably better than the ADF system for feed energy estimation in beef cattle diets, even at low feed intakes per unit of body weight.

\section{Introduction}

The evaluation of a feedstuff in terms of the energy that is available to the animal that consumes it becomes somewhat elusive since the digestibility of the fiber fraction is quite variable due to the plant's environment during growth (heat units and moisture), along with the plant's maturity at harvest and plant genetic variation. The acid detergent fiber (ADF) content, lignin and total tract neutral detergent fiber digestibility (TTNDFd) have been used to compare which system provides the most reliable method of assessment of the energy content of the feedstuff in terms of its digestibility and subsequent utilization by Angus, late summer calving cows.

The ADF method does not measure digestibility, but rather the concentration of ADF in the feed. A higher ADF concentration assumes a reduction in digestibility. For instance, the equation used to calculate total digestible nutrients $(\mathrm{TDN})$ from $\mathrm{ADF}$ with corn silage is: $\mathrm{TDN} \%=$ 87.84 - (ADF\% x 0.70).

Generally this works in terms of relative maturity since as a forage becomes more mature, the ADF fraction increases and the digestibility is reduced. Different plants have different fiber characteristics though so unique TDN from ADF calculations exist for grasses, legumes, cereal plants and other feedstuffs. Thus there are essentially as many TDN from ADF calculations as there are feedstuffs. Likewise this ADF methodology does not address the situation where ADF fractions are the same, but digestibility still is different between samples. For instance with the corn silage example just presented, we may have two varieties of corn silage both containing $28 \% \mathrm{ADF}$. The lignin component of the ADF of one sample may be slightly higher than the other sample and because of this there is a reduction in the digestibility and energy yield in the sample containing higher lignin. The Ohio Agricultural Research and Development Center (OADRC) method was used in the National Research Council (NRC) Dairy 2001 publication to address this concept more accurately. Still there are a number of other subtle issues that need to be addressed such as the rate of digestion brought on by the NDF structure and the passage rate of the feed. Here the TTNDFd methodology developed by Dave Combs at the University of Wisconsin is used and provides a measure of total NDF disappearance by using with fiber digestion time points in a standardized digestive media.

With a better estimation of NDF digestibility and applied to the National Academies of Science, Engineering and Medicine (NASEM) 2016 Beef publication's Total Digestible Nutrients (TDN) equation a more accurate calculated dietary metabolizable energy (ME) and net energy (NE) should be possible.

\section{Materials and Methods}

Multiparous Angus cows, due to calve in September at the Iowa State University - McNay Memorial Research and Demonstration Farm, were randomly separated into four diet treatments. Within these four groups cows were grouped into one of four pens based on body weight placing the cows of similar weights together to negate bunk competition. Average empty cow weights per cow per pen ranged from 1040 pounds to over 1400 pounds. All cows were starting the eighth month of pregnancy. Cows were weighed and $12^{\text {th }}$ rib fat and ribeye areas measured by ultrasound image on and off test to determine body condition score.

Sixteen pens of three cows each were used to test four diet treatments. The four treatment diets were based on common dry lot, cow rations used in the Midwest (refer to Table 1). These rations were fed at constant levels throughout the eight-week trial with the same amount given to each pen of cows with the realization that they may be inadequate from a caloric intake standpoint. The hay was a

Copyright (C) 2020 by the Authors. This is an open access article published under the CC BY-NC license (https://creativecommons.org/licenses/by-nc/4.0/), which allows for non-commercial reuse with proper attribution. 
mixed grass hay (primarily fescue), the corn was dry, whole, shell corn. The dry distillers grain (DDG) was derived from corn. Feeds were sampled every two weeks while cows were on test. Cows were weighed and scanned at the start and at the end of the eight weeks. Feed nutrient and digestibility, including the Comb's TTNDFd, evaluation was performed by Rock River Laboratory, Inc. (Watertown, WI). Cow weight change performance was measured and projected using the NASEM 2016 Beef Cattle publication methodology with the energy values provided by the Rock River Laboratory reports generated from these feedstuffs. A two sample T test assuming equal variance was then performed to determine if the equation projected weight change and the actual weight change was different.

\section{Results and Discussion}

Test results of the hay can be observed in Table 2 . The values were quite close among samples and this was expected since the feedstuffs were from a similar source and harvested at the same time point. The TDN are also provided in Table 3. Although the feedstuff is the same the estimated energy that these calculations arrive at are quite different. Table 4 a provides the comparison between actual and projected weight change after accounting for fill and fetal calf weight change.

From Table 4a, which includes all treatment rations, using the NASEM Beef 2016 energy calculations adapted to incorporate TTNDFD resulted in the bias between projected weight and actual weights being the least. The calculation using ADF generated the greatest bias, overestimating the digestibility of the hay and subsequent weight change in the cows. This can be interpreted to mean that the NASEM Beef 2016 energy calculations, adapted to include TTNDFD, offered an improved prediction for weight change relative to the ADF calculations. Likewise, the TTNDFD calculation provided the best correlation between the two measures and the $\mathrm{T}$ test showed the least difference between actual and estimated weight change as well. The T test would indicate in Table $4 \mathrm{a}$ that there was indeed a difference between the actual and projected performance across all systems, thus no system is statistically adequate. However, when just the hay only ration treatments were observed, out of all the treatments, the $\mathrm{T}$ values were all greater than 0.05 suggesting the systems all can work and the NRC 2001 Dairy methodology gave a better fit in this situation. In reality, though, usually more than one ingredient is fed, but the TTNDFD calculation was only determined on the hay from the lab analysis and with this, using a constant rate of passage $(\mathrm{Kp})$ and rate of digestion $(\mathrm{Kd})$ value in the determination. The other ingredients were valued in terms of energy from some other method rather than TTNDFD by the lab.
In Table 5, the TTNDFD was used in a more proper context where the $\mathrm{Kp}$ and $\mathrm{Kd}$ values were calculated on each of the pens prior to applying the TTNDFD /NASEM equation. In this situation TTNDFD becomes even more powerful in providing an estimation of performance and relative value of the feedstuff at hand. This is an example of how TTNDFD could be incorporated within diet formulations, where animal inputs are known.

The ADF based TDN energy calculations over estimated weight change by approximately 66 pounds per cow, whereas the NASEM Beef 2016 +TTNDFD equations reduced this error to roughly 17 pounds per cow over the trial. In commercial cow/calf nutrition, using the ADF based calculations can result in energy deficiencies in situations as this experiment. The NASEM Beef 2016 +TTNDFD equations appear more appropriate, and will allow more suitable diets formulated to avoid such deficits during high energy requirement feeding months over winter.

\section{Acknowledgements}

The authors would like to Iowa State University McNay Research Farm and Rock River Laboratory Inc. for their assistance with this project. 
Table 1.0 Treatment rations

\begin{tabular}{llll}
\hline Ration & Ingredients & Pounds Dry Matter-Daily Allowance & Ration NDF\% \\
\hline Hay & Hay & 18.1 & 59.9 \\
Hay+Corn & Hay & 19.2 & 46.7 \\
& Whole corn & 6.5 & \\
Hay+Corn+Dry & Hay & 19 & 54.4 \\
Distillers Grain & Whole Corn & 2.9 & \\
& Distillers Grain & 0.9 & \\
Hay+Dry Distillers & Hay & 21.7 & 55.1 \\
Grain & Distillers Grain & 5.6 & \\
\hline
\end{tabular}

Table 2 Hay test results

\begin{tabular}{cccccc}
\hline ADF \% & Range & Lignin \% & Range & TTNDFd \% of NDF & Range \\
\hline 43.2 & $41.5-45.1$ & 9.0 & $8.3-9.7$ & 32.5 & $28.7-34.8$ \\
\hline
\end{tabular}

Table 3 Hay test calculated TDN energy results

\begin{tabular}{cccccc}
\hline ADF to TDN & Range & Lignin to TDN & Range & TTNDFd to TDN & Range \\
\hline 58.1 & $56.6-59.5$ & 49.8 & $47.6-50.8$ & 42.3 & $40.9-44.2$ \\
\hline
\end{tabular}

Table 4a *Actual weight change and calculated weight change - over all diets ADF Methodology NRC Dairy 2001 (lignin) NASEM Beet 2016+TTNDFd

Bias (in pounds)

\begin{tabular}{llll} 
(Actual-Projected) & 65.7 & 37.9 & 17.3 \\
Correlation & 0.64 & 0.66 & 0.78 \\
$\mathrm{P}(\mathrm{T}<=\mathrm{t})$ & $4.59 \times 10^{-7}$ & 0.0001 & 0.003 \\
\hline
\end{tabular}

Table 4b *Actual weight change and calculated weight change - hay diet only

\begin{tabular}{lccc}
\hline \multicolumn{2}{c}{ ADF Methodology } & NRC Dairy 2001 (lignin) & NASEM Beet 2016+TTNDFd \\
\hline Bias (in pounds) & & & \\
(Actual-Projected) & 17.0 & 0.8 & 8.3 \\
Correlation & 0.99 & 0.99 & 1.00 \\
$\mathrm{P}(\mathrm{T}<=\mathrm{t})$ & 0.06 & 0.92 & 0.19 \\
\hline
\end{tabular}

*Note that if the rate of passage and digestibility (Kp and $\mathrm{Kd}$ ) for the TTNDFd calculation was set to a constant for all treatments and all pens within treatments.

Table 5 TTNDFd with Kp and Kd calculated prior to determining bias

Over all diets

Hay diets only

Bias (in pounds)

(Actual-Projected)

Correlation

$\underline{\mathrm{P}(\mathrm{T}<=t)}$
15.8

0.71

0.012
1.5

0.99

0.82 